\title{
IDENTIFIKASI KERUSAKKAN MESIN BERDASARKAN SINYAL GETARAN DALAM DOMAIN FREKWENSI, STUDI KASUS DI PT. FREEPORT INDONESIA
}

\author{
Ramses Yohannes Hutahaean \\ Program Studi Teknik Mesin, Fakultas Teknologi Industri dan Kebumian, \\ Universitas Sains dan Teknologi Jayapura, \\ Jl Raya Sentani-Padang Bulan, Abepura, Jayapura Telp (0967), 581659, 582449, 583259, FAX, \\ (0967)582550 \\ ramses.yh@gmail.com
}

\begin{abstract}
Abstrak
Strategi pemeliharaan mesin sangat penting dalam industri pertambangan, industri produksi semen atau industri lain sehingga diperlukan strategi perawatan yang sesuai berdasarkan kondisi operasi industri. Strategi pemeliharaan untuk untuk produksi 24 jam tentu saja tidak sama dengan strategi pemeliharaan dalam kondisi kerja normal. Pada makalah ini disajikan strategi pemeliharaan pro aktif, dimana pada strategi pemeliharaan pro aktif mensyaratkan berbagai investigasi kerusakkan mesin, investigasi kerusakkan mesin pada makalah ini menggunakan analisa sinyal getaran, dimana sinyal getaran tersebut dapat memberikan informasi kondisi kesehatan mesin sebelum mengalami kegagalan. Analisa sinyal getaran dapat dilakukan dengan menggunakan analisa getaran dalam domain frekwensi atau analisa getaran dalam domain waktu. Analisa getaran dalam domain frekwensi umumnya dilakukan untuk melakukan analisa getaran dalam kasus ketidakseimbangan, misalignment, cacat bantalan, kavitasi, kerusakan motor listrik. Sedangkan analisa getaran dalam domain waktu digunakan anlisa cacat roda gigi dengan putaran dibawah $600 \mathrm{rpm}$. Pada makalah ini ditemukan kasus baru pada bantalan yaitu kondisi terjadinya gesekan antara inner race dengan poros puli yang menyebabkan getaran tersebut teredam dan tidak memberikan informasi yang tepat, hal tersebut diketahui setelah memeriksa turunnya amplitudo getaran setelah pemeriksaan satu bulan sebelumnya, kemudian amplitudo getaran tiba tiba menurun, dan terjadi kerusakkan secara tiba tiba tanpa dapat diprediksikan.
\end{abstract}

Kata kunci : Bantalan, domain frekwensi, domain waktu, sinyal getaran

\begin{abstract}
The maintenance strategy of machines is very important in the mining industry, the cement production industry or other industries so that an appropriate maintenance strategy is needed based on industrial operating conditions. The maintenance strategy for 24-hour production is certainly not the same as the maintenance strategy under normal working conditions. In this paper a pro-active maintenance strategy is presented, where the pro-active maintenance strategy requires various investigations of failure of machine components, investigation of machine failures in this paper using vibration signal analysis, where the vibration signal can provide information on the health condition of the machine before failure. Vibration signal analysis can be done using vibration analysis in the frequency domain or vibration analysis in the time domain. Vibration analysis in the frequency domain is generally carried out to conduct vibration analysis in cases of imbalance, misalignment, bearing defects, cavitation, damage to electric motors. While the vibration analysis in the time domain is used to analyze gear defects with rotation under $600 \mathrm{rpm}$. In this paper a new case was found in the bearing which is the condition of friction between inner race bearing with the pulley shaft which causes the vibration to be damped and does not provide precise information, and damage occurs suddenly without being able to predict.
\end{abstract}

Key words : Bearing, frequency domain, time domain, vibration signal

15 Hutahaean, Ramses Yohannes; Identifikasi Kerusakkan Mesin Berdasarkan Sinyal Getaran Dalam Domain Frekwensi, Studi Kasus Di Pt. Freeport Indonesia 


\section{PENDAHULUAN}

Proses pemeliharaan mesin adalah hal yang sangat penting dalam industri manufaktur, pertambangan atau industri lainnya. Pemilihan strategi pemeliharaan yang salah dapat menyebabkan kerugian berupa kehilangan produksi. Jika kita menerapkan metode pemeliharaan berdasarkan break down maintenance, maka akan ditemui kehilangan produksi, karena kita tidak dapat memastikan kondisi mesin, selain itu diperlukan gudang yang luas untuk penyimpanan komponen komponen pengganti, sedangkan jika kita menerapkan strategi dengan memeriksa kondisi mesin dan dapat memperkirakan waktu penggantian komponen, make resiko kehilangan produksi dapat di minimalisir dan tidak diperlukan gudang yang luas, karena jika kita dapat memperikan umur komponen, kita dapat memesan dari vendor atau supplier.

Secara umum filosopi untuk sistem pemeliharaan (maintenance) dibagi dalam empat kategori.

- Breakdown maintenance proses maintenance dilakukan hingga mesin mengalami kerusakan. Kerugian metode ini adalah kita tidak dapat mengantisipasi kapan kerusakan bisa terjadi, dan dapat menyebabkan kerusakan sekunder yang terjadi, umumnya kerusakan suatu komponen yang sudah parah akan mengakibatkan kerusakan komponen lainnya. Misalkan suatu susunan pompa dengan motor, dan jika pompa tersebut sudah rusak, dan dibiarkan sampai gagal maka terdapat kemungkinan motor yang menggerakan pompa tersebut ikut rusak.

- Preventive maintenance atau maintenance berdasarkan waktu, biasanya dilakukan jadwal perawatan dalam waktu tertentu, kerugian metode ini adalah sering ditemui bahwa terjadi kerusakkan sebelum dilakukan perbaikkan pada jadwal yang telah ditentukan, atau pada saat dilakukan pergantian komponen mesin ditemui bahwa kondisi komponen tersebut dalam keadaan baik.

- Predictive maintenance atau maintenance berdasarkan kondisi (condition-based maintenance). Metode ini dilakukkan dengan melakukan pemeriksaan berkala, sehingga dapat ditentukan pada jadwal perawatan terdekat komponen komponen apa saja yang dilakukan, pemeriksaan yang dilakukan dapat berupa oil analysis, vibration analysis, thermographi.

- Proactive maintenance atau prevention maintenance. Maintenance tipe ini adalah dengan melakukan continuous improvement, dengan melakukan analisa penyebab kerusakan, dan kemudian melakukan perancangan untuk membuat agar komponen mesin mempunyai lifetime yang lebih lama.

Pada makalah ini ditunjukkan metode proactive maintenance, yaitu dengan melakukan investigasi suatu kerusakkan suatu mesin yang tidak terprediksi sebelumnya dan dilakukan analisa sinyal getaran, kemudian memberikan beberapa rekomendasi agar kejadian kerusakkan yang sama tidak terulang lagi.

\section{DASAR TEORI}

\section{Transformasi Fourier}

Pada praktek dilapangan apakah itu di industri pertambangan minyak, pertambangan mineral ataupun alat berat, sinyal getaran yang terjadi pada peralatan bukan berupa sinyal harmonik yang tidak sederhana, maka kita perlu melakukan identifikasi sinyal frekwensi berapa saja yang ada. Untuk melakukan investigasi kerusakkan kita biasanya akan melihat bentuk sinyal dalam domain frekwensi, pada domain frekwensi kita dapat mengidentifikasikan penyebab getaran mesin, apakah karena misalignment, bearing defect, unbalance dan lain lain. Sinyal dalam domain waktu dapat kita transformasikan kedalam domain frekwensi dengan menggunakan transformasi Fourier. Seperti ditunjukkan pada gambar 1 dan 2 .

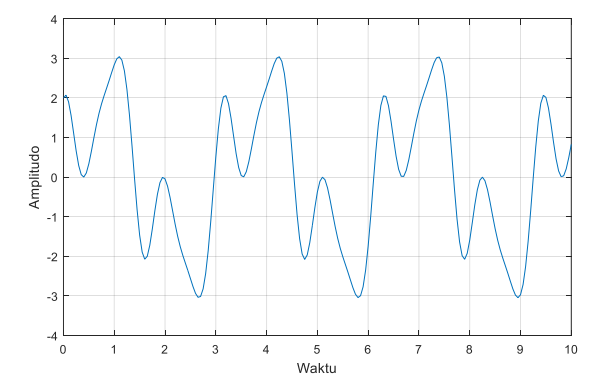

Gambar 1 Fungsi $y=2 \sin (2 t)+1.5 \cos (6 t)+$ $0.5 \cos (10 t)$ dalam domain waktu

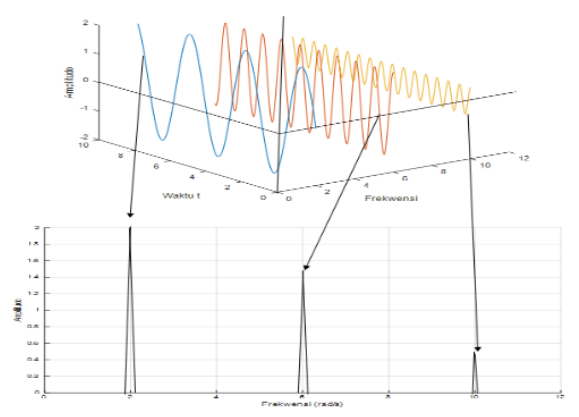

16 Hutahaean, Ramses Yohannes; Identifikasi Kerusakkan Mesin Berdasarkan Sinyal Getaran Dalam Domain Frekwensi, Studi Kasus Di Pt. Freeport Indonesia 
Gambar 2 Fungsi $y=2 \sin (2 t)+1.5 \cos (6 t)+$ $0.5 \cos (10 t)$ dalam domain frekwensi

Transformasi Fourier dapat berupa, CFT ( Continuous Fourier Transform ), DFT ( Discrete Fourier Transform ), FFT ( Fast Fourier Transform ). Pada makalah ini hanya ditunjukkan transformasi Fourier kontinyu, seperti ditunjukkan oleh persamaan berikut.

$$
\begin{aligned}
& a_{n}=\frac{2}{T} \int_{0}^{T} F(t) \cos n \omega t d t \quad n=1,2, \ldots \ldots \\
& b_{n}=\frac{2}{T} \int_{0}^{T} F(t) \sin n \omega t d t \quad n=1,2, \ldots \ldots . .
\end{aligned}
$$

Dimana :

$a_{n}=$ Koefisien cosinus

$b_{n}=$ Koefisien sinus

\section{Identifikasi Kerusakan Mesin Berdasarkan Sinyal Getaran}

Identifikasi kerusakan berdasarkan sinyal getaran secara umum terbagi dua, yang pertama adalah dengan mengidentifikasikan berdasarkan frekwensi getaran, umumnya digunakan untuk melakukan identifikasi yang disebabkan oleh kasus unbalance, misalignment, kavitasi, turbulensi, kerusakkan pada bantalan, motor listrik dan lain lain. Sedangkan identifikasi berdasarkan domain waktu atau waveform, umumnya digunakan untuk melihat kerusakkan pada pasangan roda gigi.

\section{Identifikasi Kasus Unbalance Dan Missalignment}

\section{Unbalance}

Massa tak balans adalah salah satu penyebab utama getaran, kondisi tak balans ( unbalance ) adalah suatu kondisi dimana pusat massa tidak berimpit dengan pusat rotasi, seperti ditunjukan pada gambar 3 .

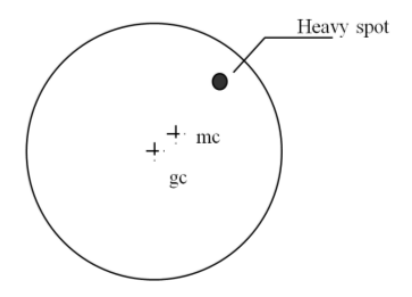

\section{Gambar 3 Kondisi unbalance}

Sedangkan dalam bentuk domain frekwensi, bentuk spektrum getaran akibat unbalance ditnjukkan pada gambar 4, seperti terjadi pada kasus tobelo fan di PT.Freeport Indonesia.

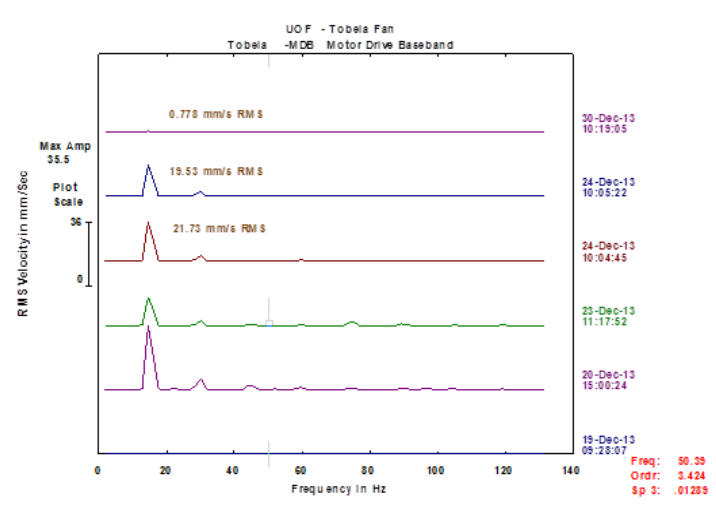

\section{Gambar 4 Bentuk sinyal getaran kasus unbalance dalam domain frekwensi.}

\section{Missalignment}

Missalignment adalah kondisi dimana poros pada motor penggerak tidak membentuk sebuah garis lurus dengan komponen yang digerakkan, misalkan pompa, puli dan lain lain. Bentuk missalignment terdapat dua jenis, missalignment paralel dan missalignment angular sepeti ditunjukkan pada gambar 5 .

$$
\text { Driver Machine Driven Machine }
$$

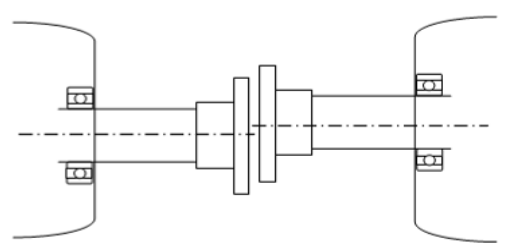

(a)

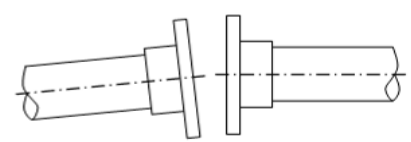

(b) Gambar 5 Kondisi missalignment. (a) Paralel (b)
Angular

Sedangkan bentuk sinyal getaran kasus missalignment paralel dalam domain frekwensi ditunjukan pada gambar 6, dan untuk missalignment angular ditunjukkan pada gambar 7. Satuan orde adalah menunjukan kelipatan dari kecepatan putaran poros. 


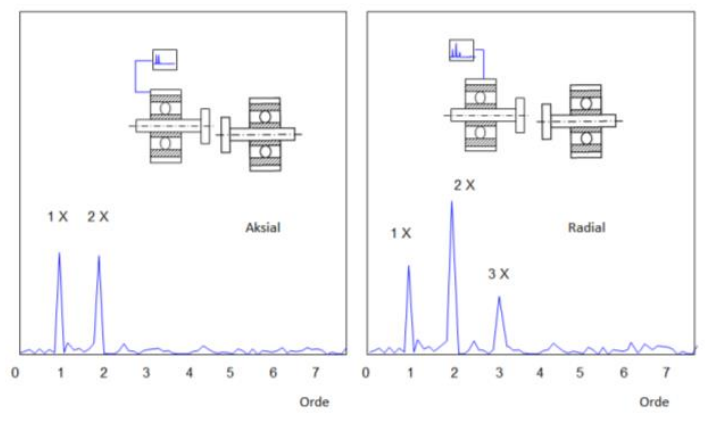

Gambar 6 Spektrum missalignment paralel

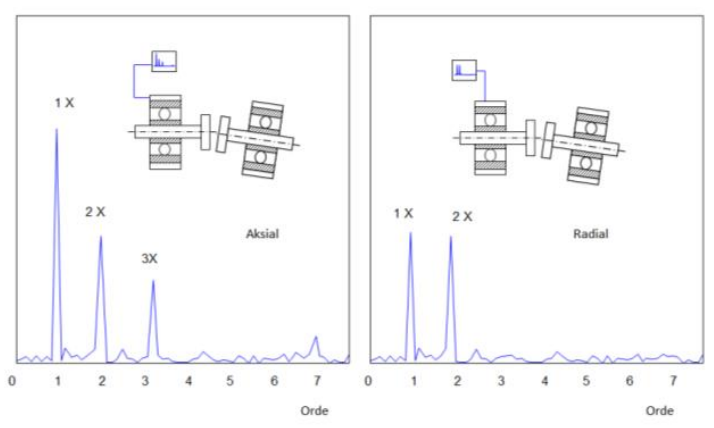

Gambar 7 Spektrum missalignment angular

\section{Identifikasi Kerusakan Bantalan}

Kegagalan bearing (Bantalan) disebabkan oleh beberapa penyebab dasar yaitu :

- Kontaminasi, termasuk kelembaban

- Overstress ( tegangan yang berlebih )

- Cacat produk

- Lifetime

Getaran pada bantalan terjadi pada beberapa frekwensi. Dengan mengetahui frekwensi getaran maka kita dapat melakukan diagnosa masalah. Bantalan roller mempunyai frekwensi dan tones yang spesifik. Bantalan roller mempunyai 4 jenis tones :

- Fundamental train frequency ( FTF )

- Ball spin frequency (BS)

- Outer race ( OR )

- Inner race ( IR )

Rumus rumus untuk menghitung frekuensi spesifik tersebut adalah :

$$
\begin{aligned}
& F T F=\frac{r p s}{2}\left[1-\frac{B d}{P d} \cos \phi\right] \\
& B S=\frac{P d}{2 B d}(r p s)\left[1-\left(\frac{B d}{P d}\right)^{2} \cos ^{2} \phi\right] \ldots \\
& O R=N(F T F) \\
& I R=N(r p s-F T F) \text {. }
\end{aligned}
$$

\section{dimana}

rps $=$ putaran per detik.

$\mathrm{Bd}=$ diameter bola/roller

$\mathrm{Pd}=$ Diameter pitch.

$\mathrm{N}=$ Jumlah bola/roller

$\phi=$ Sudut kontak

Rumus-rumus tersebut adalah teoritis dan perbedaan antara perhitungan dan pengukuran dapat terjadi pada beberapa $\mathrm{Hz}$. Beban awal dapat menyebabkan berubahnya sudut kontak, perubahan sudut kontak menyebabkan frekwensi outer race yang aktual lebih tinggi dari hasil perhitungan.
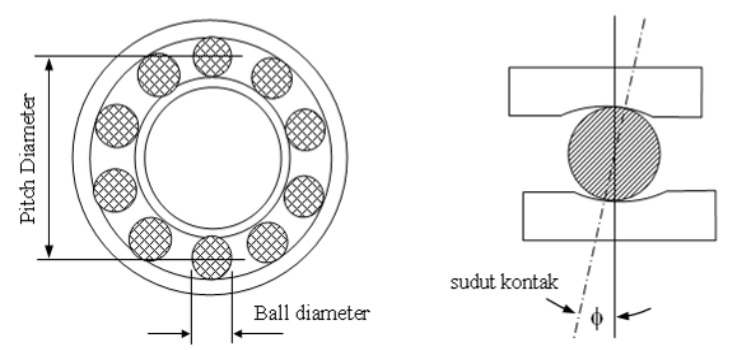

\section{Gambar 8 Bantalan}

Namun produsen bantalan telah mengeluarkan tabel tabulasi frekwensi bantalan (bearing), seperti ditunjukkan pada tabel 1.

Tabel 7 Faktor Frekuensi Bantalan

\begin{tabular}{l|l|l|l|l}
\hline $\begin{array}{l}\text { Merk } \\
\text { Bantalan }\end{array}$ & FTF & BS & OR & IR \\
\hline FAG 6311 & 0.378 & 1.928 & 3.024 & 4.976 \\
SKF 6311 & 0.382 & 2.003 & 3.057 & 4.943 \\
NTN 6311 & 0.384 & 2.040 & 3.072 & 4.928 \\
\hline
\end{tabular}

Jika tabel bantalan tidak tersedia, maka frekwensi bantalan dapat didekati dengan rumus sederhana sebagai berikut :

$$
\begin{aligned}
& F T F=0.4 \times \text { Speed } \\
& \text { OR }=0.4 \times \text { Speed } \times N \\
& I R=0.6 \times \text { Speed } \times N
\end{aligned}
$$

\section{STUDI KASUS}

\section{Fakta Fakta Yang Di Kumpulkan}

Pada tanggal 17 September 2009 jam 07.02 terjadi penghentian operasi conveyor 64 , hal ini disebabkan terbakarnya bantalan sebelah kiri puli 
pada Drive A. Kemudian dilakukan investigasi dengan mengumpulkan bukti bukti fisik sebagai berikut.

1. Bantalan pada puli drive A sebelah kiri mengalami kegagalan.

2. Karena kerusakkan terjadi pada inner race ( gambar 10 ), maka yang perlu kita hitung adalah nilai frekwensi inner race. Nilai IR dengan data data $\mathrm{N}=20$, kecepatan $62.5 \mathrm{rpm}$ adalah

3. $I R=0.6 \times 62.5 \times 20=750 \mathrm{rpm}$ atau $12.5 \mathrm{~Hz}$.

4. Ditemukan kondisi pelumas yang masih penuh, sepeti ditunjukkan pada gambar 9.

5. Terdapat retakan pada bagian inner race seperti ditunjukkan pada gambar 10 .

6. Terdapat bekas gesekan pada poros yang berkontak dengan inner race, seperti ditunjukkan pada gambar 11 .

7. Amplitudo getaran dalam arah radial pada saat terakhir pengukuran tanggal 9 September 2009 adalah $0.65 \mathrm{~mm} / \mathrm{sec}$ dan terjadi pada frekwensi $62.5 \mathrm{~Hz}$ yang merupakan harmonik ke 5 dari frekwensi inner race $(12.5 \mathrm{~Hz}$ x $5=62.5 \mathrm{~Hz})$, namun belum sigifikan, seperti ditunjukkan pada gambar 12 .

8. Amplitudo getaran dalam arah aksial memiliki amplitudo terbesar pada tanggal 27 April 2009 sebesar $0.243 \mathrm{~mm} / \mathrm{sec}$ pada harmonik pertama, dan sebesar $0.8 \mathrm{~mm} / \mathrm{sec}$ pada harmonik ke 5, namun pada pengukuran berikut tanggal 16 Juni 2009, getaran pada harmonik pertama hingga harmonik ke 10, turun secara signifikan, seperti ditunjukkan pada gambar 13 .

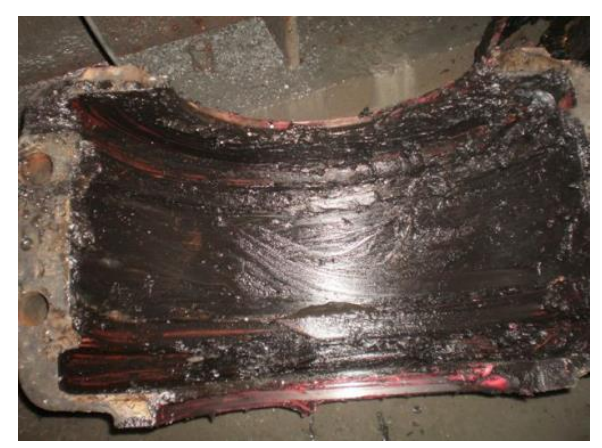

Gambar 9 Kondisi bantalan yang masih terisi pelumas

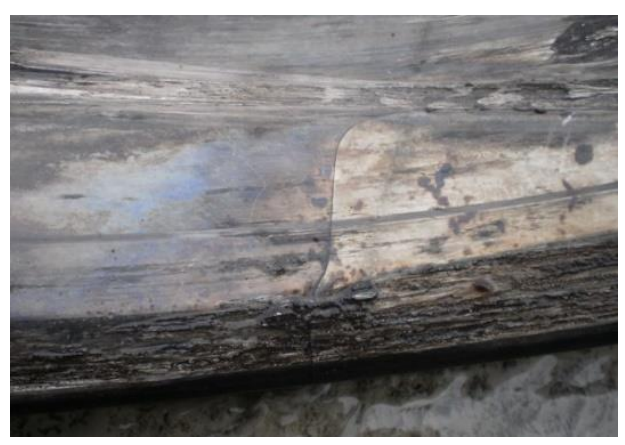

Gambar 10Retakan pada Inner race bantalan

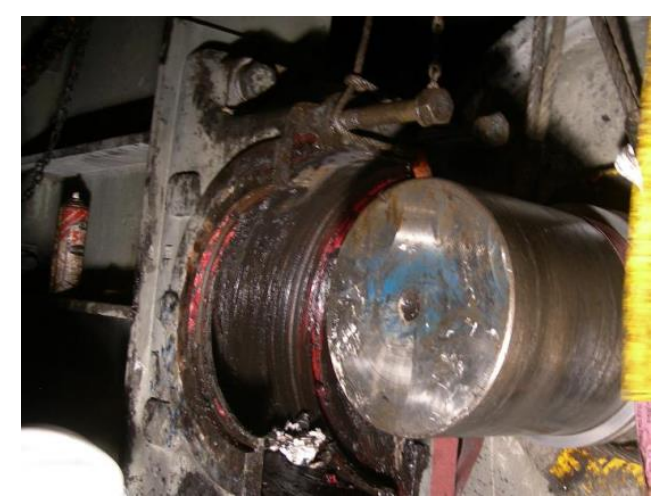

Gambar 11 Bekas gesekan pada poros

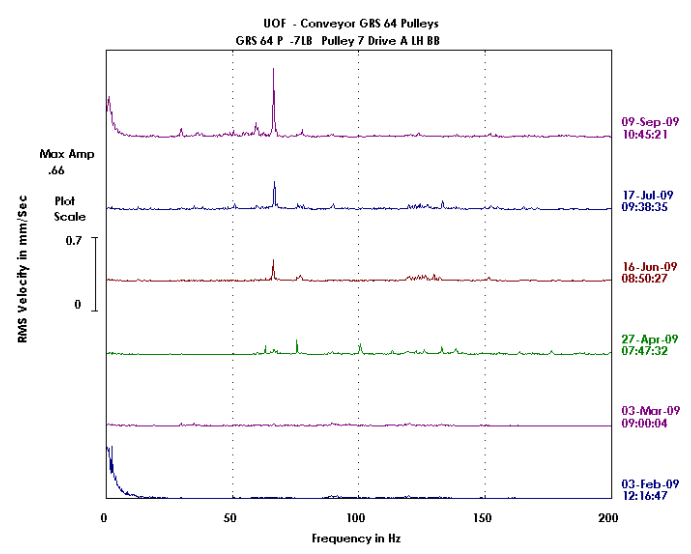

Gambar 12 Histori getaran dalam arah radial 


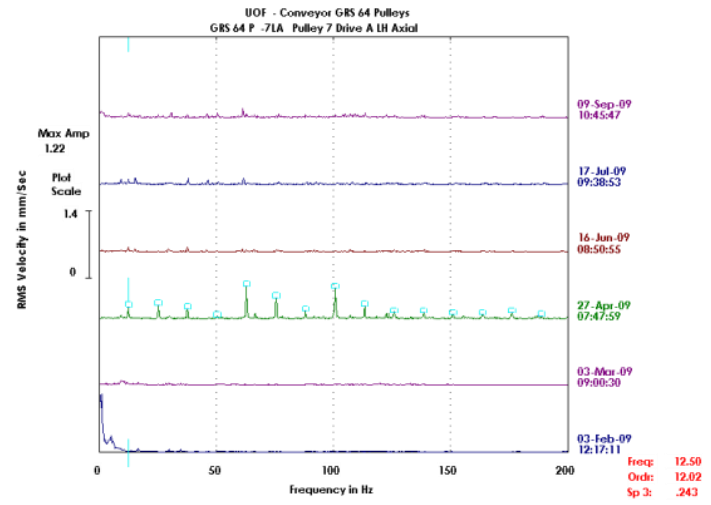

Gambar 13 Histori getaran dalam arah aksial

\section{Analisa Kegagalan Bantalan Pada Conveyor 64.}

Terdapat beberapa kemungkinan penyebab kegagalan bantalan, pertama kemungkinan kurangnya pelumas, namun kemungkinan ini dipatahkan oleh fakta no 3 dan gambar 9, dimana masih ditemukan jumlah pelumas yang cukup. Kemungkinan kedua, kerusakkan outer race, dari perhitungan frekwensi, frekwensi yang cocok adalah frekwensi inner race seperti ditunjukkan fakta nomor 2, 4, gambar 13, dimana pada gambar 13 ditunjukkan frekwensi inner race yang diperoleh dari hasil pengukuran. Kemudian dari gambar 13 dapat diketahui bahwa amplitudo pada frekwensi inner race, nilai maksimumnya terjadi pada tanggal 27 April 2009, kemudian amplitudo getaran menurun pada pengukuran berikutnya, dan secara logika tidak mungkin bantalan bisa memperbaiki diri sendiri, sehingga amplitudo getaran menurun, dan berdasarkan fakta nomor 4 dan 5 telah terjadi gesekan antara inner race dan poros yang menyebabkan getaran teredam dan mengakibatkan amplitudo getaran menurun.

\section{Rekomendasi Untuk Bantalan Pada Conveyor}

Berdasarkan hasil analisa, maka diberikan rekomendasi yang harus diterapkan pada seluruh bantalan pada conveyor sebagai berikut :

1. Terjadi gesekan antara inner race dan poros puli, dimana inner race seharusnya tidak berputar terhadap poros, hal ini menyebabkan getaran tersebut teredam seperti ditunjukkan pada gambar 13. Dan jika terjadi simpton seperti ditunjukkan pada gambar 13, dimana terjadi penurunan amplitudo getaran secara signifikan, segera direncanakan penggantian bantalan pada jadwal terdekat.

2. Pada saat pemasangan bantalan dilakukan suaian yang lebih ketat antara inner race dan poros conveyor.

\section{KESIMPULAN}

Berdasarkan hasil analisa, diperoleh kesimpulan sebagai berikut :

1. Analisa getaran pada bantalan dilakukan dengan menggunakan domain frekwensi.

2. Pada kasus bantalan, jika terjadi penurunan amplitudo getaran secara signifikan pada inner race, maka telah terjadi gesekan antara inner race dan poros sehingga menyebabkan getaran tersebut teredam, dan terlihat pada spektrum yang ditunjukan pada gambar 5dimana spektrum getaran harmonik menghilang atau berkurang pada tanggal 27 April 2009.

3. Jika ditemukan kasus penurunan amplitudo getaran secara signifikan, maka harus segera dilakukan penggantian bantalan pada overhaul terdekat.

4. Investigasi kerusakkan bantalan dengan menggunakan analisa getaran dalam domain frekwensi dapat diterapkan pada industri.

\section{DAFTAR PUSTAKA}

[1] Abele E., Altintas Y. and Brecher C. (2010), "Machine Tool Spindle Units," CIRP AnnalsManufacturing Technology, vol. 59, no. 2, pp. 781-802.

[2] Cunha, E. Caetano, P. Ribeiro, G. Müller (eds.), Proceedings of the 9th International Conference on Structural Dynamics, EURODYN 2014, Porto, Portugal, 30 June - 2 July 2014,

[3] Dimaragonas. Andrew D., Sam Hadad, “ Vibration for Engineers" Prentice Hall, New York, 1992.

[4] Girdhard. Paresh., Scheffer,C. "Practical Machinery Vibration Analysis and Predictive Maintenance". Elseiver 1998.

[5] Inman J. Daniel." Engineering Vibrations “ .Pearson Education International, $3^{\text {rd }}$ edition, New Jersey 2008.

[6] ISO 10816-1: Mechanical vibration-Evaluation of machine vibration by measurements on nonrotating parts-Part 1: General guidelines. ISO Switzerland, 1995.

$[7]$

[8] ISO 10816-3: Mechanical vibrationEvaluation of machine vibration by measurements on non-rotating parts-Part 3: Industrial machines with nominal power above $15 \mathrm{~kW}$ and nominal speeds between $120 \mathrm{r} / \mathrm{min}$ and 15,000 r/min when measured in situ. ISO Switzerland, 2009.

[9] ISO 7919-1: Mechanical Vibration of nonreciprocating machines - Measurements on

20 Hutahaean, Ramses Yohannes; Identifikasi Kerusakkan Mesin Berdasarkan Sinyal Getaran Dalam Domain Frekwensi, Studi Kasus Di Pt. Freeport Indonesia 
rotating shafts and evaluation criteria-Part 1: General guidelines. ISO Switzerland, 1996.

[10]ISO/TR 230-8:2009 (2009), "Test code for machine tools -- Part 8: Vibrations".

[11] Martin K. F. (1994), “A Review by Discussion of Condition Monitoring and Fault Diagnosis in Machine Tools," International Journal of Machine Tools and Manufacture, vol. 34, no. 4, pp. 527-551.

[12]Mobius Institute (2016), "Vibration Analysis Training Course Book".

[13]Mobius Institute (2017), "Vibration Analysis Definitions", Available at: http://mobiusinstitute.com/.

[14]Morando, L. (1996), "Technology overview: Shock Pulse Method," Proceedings of a Joint Conference, Mobile, Alabama.

[15]Randall, R. B. (2011), "Vibration-based condition monitoring: industrial, aero-space and automotive applications", John Wiley \& Sons.

[16]Rastegari A. and Bengtsson M. (2014), "Implementation of Condition Based
Maintenance in Manufacturing Industry", IEEE International Conference on Prog-nostics and Health Management, Washington, USA.

[17] Rastegari, A., and Bengtsson, M. (2015), "Cost Effectiveness of Condition Based Maintenance in Manufacturing Industry", IEEE 61st Annual Reliability and Main-tainability Symposium, Florida, USA.

[18]Rastegari, A., Archenti, A., and Mobin, M. (2017), "Condition Based Mainte-nance of Machine Tools: Vibration Monitoring of Spindle Units", IEEE 63nd An-nual Reliability and Maintainability Symposium, Florida, USA.

[19] Singiresu Rao.S." Mechanical Vibrations". $5^{\text {th }}$ Edition, Prentice Hall, 2011.

[20]Sundström, T. (2013), "The Shock Pulse Method and the Four Failure Stages of Rolling Element Bearings", Technical report, SPM Instruement AB.

[21]Wowk, Victor ." Machinery Vibration, Measurement And Analysis " McGraw-Hill 1991.

21 Hutahaean, Ramses Yohannes; Identifikasi Kerusakkan Mesin Berdasarkan Sinyal Getaran Dalam Domain Frekwensi, Studi Kasus Di Pt. Freeport Indonesia 